Published in final edited form as:

J Med Primatol. 2013 February ; 42(1): 48-49. doi:10.1111/jmp.12032.

\title{
How well do you know your monkeys?
}

\author{
Deepak Kaushal, PhD, \\ Tulane National Primate Research Center, Covington, LA \\ Rudolf P. Bohm Jr., DVM, DACLAM, and \\ Tulane National Primate Research Center, Covington, LA \\ Andrew A. Lackner, DVM, PhD, DACVP \\ Tulane National Primate Research Center, Covington, LA
}

\begin{abstract}
We read with interest the letter to the editor titled "How well do you know your monkey model" (1), written in response to our review article "The nonhuman primate model of tuberculosis" (J Med Primatol 41: 191-201) (2). This letter, by Engels and colleagues, raises an important issue about the use of the tuberculin skin test (TST) to detect Mycobacterium tuberculosis (Mtb) infection in nonhuman primates (NHPs). While we tend to agree with their general philosophy that improved detection of tuberculosis (TB), in particular latent $\mathrm{TB}$, requires the development of more robust technologies, their understanding of our model is inherently flawed.
\end{abstract}

The authors take for granted that all NHPs used in biomedical research are imported from nondomestic source countries. This is just not the case. The source of all Indian origin rhesus macaques in the US since the late 1970s has been from domestic breeding colonies. This was necessitated by a global ban on the export of Indian rhesus macaques by the government of India at that time. Since then, all Indian origin rhesus macaques at the NPRCs have been domestically bred and the animals are extremely well characterized with respect to infectious diseases such as tuberculosis (TB). As the authors state, rigorous preventive medicine programs have focused on maintaining negative TB status in domestic NHP colonies for many years.

The authors are correct that the highest risk of TB infection in NHP occurs in animals imported from nondomestic sources. As a result, a best practice with respect to such animals is to keep them completely segregated from domestically bred NHPs. NHP originating from areas where TB is prevalent in the human population are extensively screened prior to inclusion at these NPRCs, or not used for TB research studies. Well-characterized domestic sources of NHP or NHP imported from areas without endemic TB are considered for these particular studies. It is the result of these strategies, that no TB outbreak has been detected at the TNPRC amongst domestically bred macaques, for more than two decades now.

The author's contention that "TST commonly fails to detect infection" is an overstatement, at least with respect to rhesus macaques. In an outbreak at the TNPRC close to 10 years ago in imported Chinese origin rhesus monkeys, the TST was diagnostic and was the screening method used to effectively identify cases and contain infection to a single room. Admittedly, adding other testing modalities increased our ability to confirm the diagnosis in this 
particular group of animals. The relatively low incidence of spontaneous TB cases in the literature compared to the number of domestic NHP used in research is a testament to the effectiveness of the TST used as a screening tool. If the TST "commonly" failed to detect cases of TB in domestic breeding colonies these colonies would have a much greater prevalence of disease than is currently noted.

This contention is also supported by experimental data. In almost 125 Indian rhesus macaques experimentally infected since 2005, with Mtb CDC1551, H37Rv, Erdman or defined mutants of $M t b$ (3-8, unpublished results), here at the TNPRC, TST was able to detect $M t b$ infection. In many of these studies, which involved a vaccination component (68), TST always detected vaccination with BCG as well. In fact, we found no difference in the ability of TST and PRIMAGAM ${ }^{\circledR}$ (an interferon-gamma release assay comparable to QUANTIFERON-GOLD $\left.{ }^{\circledR}\right)$ to detect experimental $M t b$ infection in domestically bred Indian rhesus at identical time-points.

There is no argument that better TB diagnostic assays need to be developed and that the TST is far from a perfect screening tool. This is the driving force behind the development of nucleic acid based diagnostic tests for detecting human infections. However, the enthusiasm for such tests is dampened by the requirement for technology and infrastructure in resourcelimited settings.

\section{References}

1. Engels G, Wilbur AK, Jones-Engel L. How well do you know your monkey model? J Med Primatol. In press.

2. Kaushal D, Mehra S, Didier PJ, Lackner AA. The nonhuman primate model of tuberculosis. J Med Primatol. 41:191-201. [PubMed: 22429048]

3. Dutta NK, Mehra S, Didier PJ, Roy CJ, Doyle LA, Ratterree M, Alvarez X, Be N, Lamichhane G, Jain SK, Lacey MR, Lackner AA, Kaushal D. Genetic requirements for the survival of tubercle bacilli in primates. J Infect Dis. 2010; 201:1743-52. [PubMed: 20394526]

4. Mehra S, Didier PJ, Golden NA, Asher M, Doyle LA, Russell-Lodrigue K, Roy C, Blanchard JL, Veazey RS, Lackner AA, Kaushal D. Reactivation of latent tuberculosis in rhesus macaques by SIV co-infection. J Med Primatol. 2011; 40:233-43. [PubMed: 21781131]

5. Mehra S, Golden NA, Stuckey KJ, Didier PJ, Doyle LA, Russell-Lodrigue KE, Sugimoto C, Hasegawa A, Sivasubramani SK, Roy CJ, Alvarez X, Kuroda MJ, Blanchard JL, Lackner AA, Kaushal D. The Mycobacterium tuberculosis SigH is required for bacterial burden as well as immunopathology in primates. J Infect Dis. 2012; 205:1203-1213. [PubMed: 22402035]

6. Mehra S, Alvarez X, Didier PJ, Doyle LA, Blanchard J, Lackner AA, Kaushal D. Granuloma Correlates of Protection Against TB and Mechanisms of Immune Modulation by Mycobacterium tuberculosis. J Infect Dis. In press (expected publication date 01-01-2013).

7. Huang D, Shen Y, Qiu L, Chen CY, Shen L, Estep J, Hunt R, Vasconcelos D, Du G, Aye P, Lackner AA, Larsen MH, Jacobs WR Jr, Haynes BF, Letvin NL, Chen ZW. Immune distribution and localization of phosphoantigen-specific Vgamma2Vdelta2 T cells in lymphoid and nonlymphoid tissues in Mycobacterium tuberculosis infection. Infect Immun. 2008 Jan; 76(1):426-36. [PubMed: 17923514]

8. Larsen MH, Biermann K, Chen B, Hsu T, Sambandamurthy VK, Lackner AA, Aye PP, Didier P, Huang D, Shao L, Wei H, Letvin NL, Frothingham R, Haynes BF, Chen ZW, Jacobs WR Jr. Efficacy and safety of live attenuated persistent and rapidly cleared Mycobacterium tuberculosis vaccine candidates in non-human primates. Vaccine. 2009 Jul 23; 27(34):4709-17. [PubMed: 19500524] 